Document downloaded from:

http://hdl.handle.net/10251/122862

This paper must be cited as:

Benajes, J.; García Martínez, A.; Monsalve-Serrano, J.; Villalta-Lara, D. (2018). Exploring the limits of the reactivity controlled compression ignition combustion concept in a light-duty diesel engine and the influence of the direct-injected fuel properties. Energy Conversion and Management. 157:277-287. https://doi.org/10.1016/j.enconman.2017.12.028

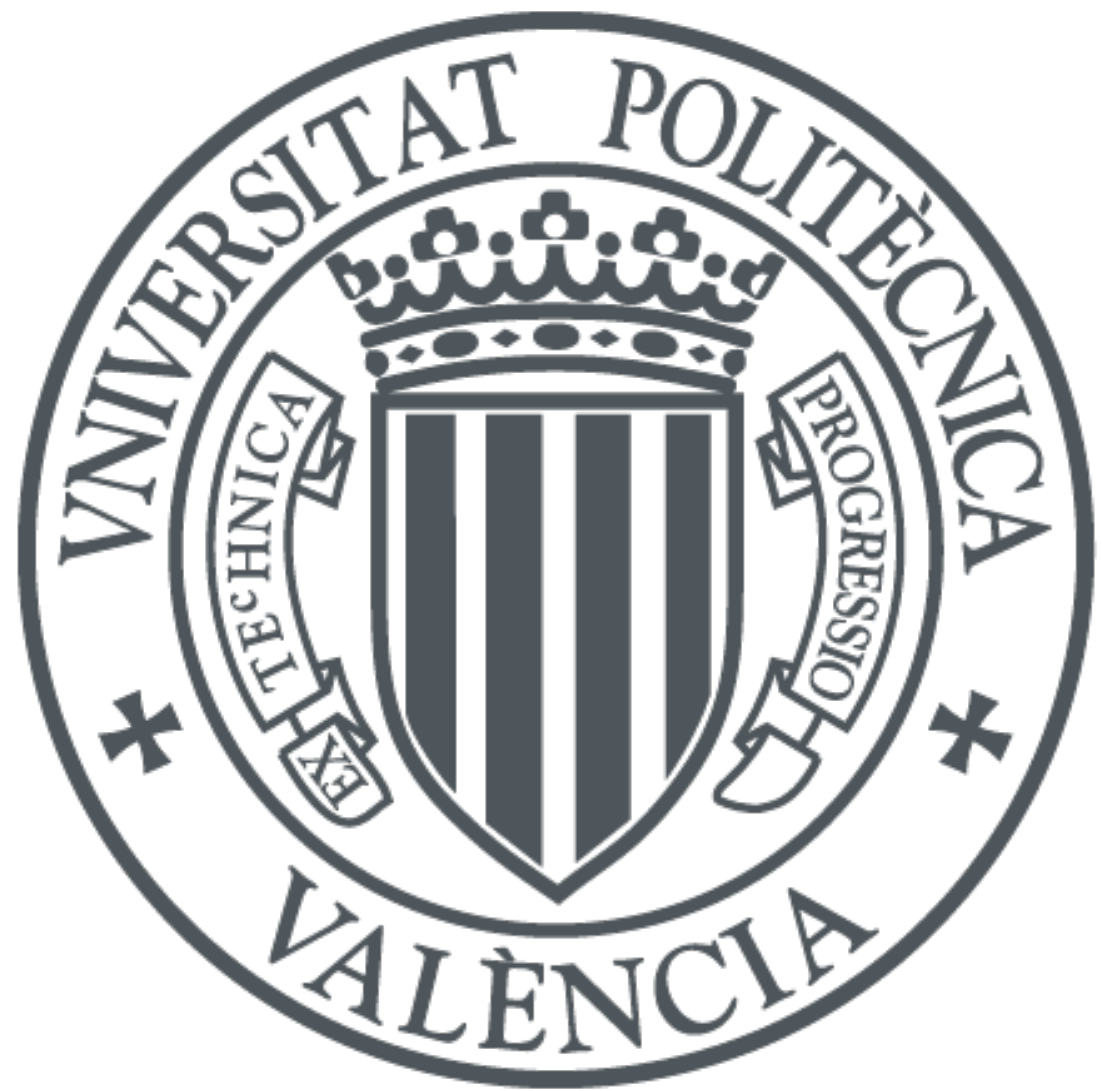

The final publication is available at

https://doi.org/10.1016/j.enconman.2017.12.028

Copyright Elsevier

Additional Information 


\title{
Exploring the limits of the reactivity controlled compression ignition combustion concept in a light-duty diesel engine and the influence of the direct-injected fuel properties
}

Energy Conversion and Management, Volume 157, 1 February 2018, Pages 277-287

https://doi.org/10.1016/j.enconman.2017.12.028

\author{
Jesús Benajes, Antonio García*, Javier Monsalve-Serrano and David Villalta \\ CMT - Motores Térmicos, Universitat Politècnica de València, Camino de Vera s/n, \\ 46022 Valencia, Spain
}

Corresponding author $(*)$ :

Dr. Antonio García (angarma8@mot.upv.es)

Phone: +34 963879659

Fax: +34963877659

\begin{abstract}
This experimental work investigates the operational limits of the reactivity controlled compression ignition combustion concept in a light-duty single-cylinder diesel engine using the stock compression ratio (17.1:1) with specific constraints. In addition, the effects of using different direct-injected fuels on engine-out emissions and performance are analyzed. First, an engine mapping was performed using diesel and gasoline as direct-injected and port-injected fuels, respectively. The operational limits of the reactivity controlled compression ignition concept have been found to be confined in the region defined from 2 to 5 bar indicated mean effective pressure at $1000 \mathrm{rev} / \mathrm{min}$ and from 4 to 8 bar indicated mean effective pressure at $3000 \mathrm{rev} / \mathrm{min}$. In that portion of the map, nitrogen oxides and smoke emissions were below $0.4 \mathrm{~g} / \mathrm{kWh}$ and 0.1 filter smoke number simultaneously, and the engine mechanical limits were respected. Later, the effects of the direct-injected fuel properties have been evaluated at the points that define the frontiers of maximum and minimum engine load in the baseline engine map (diesel/gasoline). To do this, three additional fuels based on diesel-gasoline mixings at different ratios (90\%-10\%, 70\%-30\% and 50\%-50\%), also known as dieseline, were used as direct-injected fuel instead of $100 \%$ diesel. To isolate the effects of each directinjected fuel, the same engine settings were used for the comparison. The results show that, as the reactivity gradient between the high and low reactivity fuel diminishes, the sequential autoignition achieved in reactivity controlled compression ignition due to local combustion reactions switches to a more kinetically controlled homogeneous charge compression ignition-like combustion process. Finally, all the fuels were found to be capable of operating inside the emissions restrictions imposed by doing little modifications on the baseline calibration. However, no clear potential was found versus using $100 \%$ diesel as high-reactivity fuel.
\end{abstract}

\section{Keywords}

Reactivity controlled compression ignition; Dual-fuel combustion; Engine map; Efficiency; Dieseline 


\section{Introduction}

The dual-fuel strategy commonly known as reactivity controlled compression ignition (RCCI) has a major scientific interest nowadays [1]. This strategy relies on injecting a low reactivity fuel in the intake port and a high reactivity fuel directly into the cylinder [2]. The $\mathrm{RCCl}$ combustion mode differs from the conventional dual-fuel combustion [3] in that $\mathrm{RCCl}$ relies on decoupling the end of injection of the direct injected fuel and the start of combustion [4]. This promotes a well-mixed and dilute charge [5], which provides ultra-low NOx and soot emissions [6] together with high efficiency over a wide range of engine speeds and loads [7]. The potential of the RCCI combustion concept has been demonstrated over the last years on different engine platforms: single-cylinder, multi-cylinder, heavy-duty, medium-duty and light-duty diesel engines operating with low, medium and high compression ratios. From these studies, it can be concluded that $\mathrm{RCCl}$ is able to avoid the NOx-soot trade-off appearing during conventional diesel combustion (CDC) [8] with similar or better thermal efficiency than CDC [9].

The $\mathrm{RCCl}$ concept has been proved to have greater potential than other low temperature combustion (LTC) concepts to be implemented over a wider range of operating conditions. In this sense, the homogeneous charge compression ignition $(\mathrm{HCCl})$ concept was found to be limited to the partial load range because the combustion onset is managed by the charge conditions at intake valve close (IVC), which are very sensitive to the engine operating conditions [10]. The partially premixed combustion (PPC) allows increasing the feasible operating range versus $\mathrm{HCCl}$ by promoting certain degree of fuel stratification in the chamber [11]. However, the great auto-ignition qualities of diesel fuel still imply major challenges regarding combustion control and mechanical engine stress. The gasoline PPC concept was found a suitable solution to extend the ignition delay without the need of high EGR fractions by using a fuel with higher autoignition resistance than diesel [12]. However, ignitability problems were found at low loads due to the low reactivity of the gasoline. To solve this issue, the spark assisted gasoline PPC was proposed [13]. This concept showed greater capabilities to control the combustion process at low loads, but the need of using rich equivalence ratios between the spark electrodes resulted in unacceptable NOx and soot emissions [14]. Thus, the main advantage of $\mathrm{RCCl}$ versus the other LTC techniques comes from using two fuels of different reactivity [15], which confers an additional control degree by adjusting the proportion of both fuels as required [16]. In this way, the appearance of the main limitations of the premixed LTC concepts can be somehow minimized [17]. In particular, the combustion stability at low load can be improved by reducing the low reactivity fuel (LRF) portion [18]. Even in this case, literature shows that $\mathrm{HC}$ and $\mathrm{CO}$ emissions still are a key aspect to be investigated for mitigating the low load RCCl shortcomings [19]. At high load, the high-reactivity fuel (HRF) stratification can be optimized through the direct injection settings in order to promote a more sequential autoigniton of the incylinder charge [20], thus reducing the maximum pressure rise rates (MPRR) and incylinder pressure peaks $\left(P_{\max }\right)$ compared to other LTC concepts. However, literature shows that the maximum engine load achievable with only $\mathrm{RCCl}$ regime is also restricted to moderate loads [21], which limits their application to real engines [22].

To avoid the main limitations of $\mathrm{RCCl}$, a dual-mode combustion concept can be implemented by switching to other combustion regimes in the regions of the engine map that are critical for RCCI [23]. The dual-mode RCCI/CDC has been found to be a 
potential solution to cover the whole engine map when implemented in highcompression ratio $(\approx 17: 1)$ light-duty and medium-duty engines. Thus, by applying the $C D C$ regime in the low and high load portions of the engine map, the excessive $H C$ and CO emissions and MPRR are avoided [24]. Another solution when using a lower compression ratio $(\approx 15: 1)$ is the dual-mode dual-fuel concept [25], which rely on covering the high load portion of the map through a diffusive dual-fuel combustion. This combustion strategy allows covering around $80 \%$ of the engine map with $\mathrm{NO}_{\mathrm{x}}$ and soot emissions below $0.4 \mathrm{~g} / \mathrm{kWh}$ and $0.5 \mathrm{FSN}$, respectively, showing peaks of $1.4 \mathrm{~g} / \mathrm{kWh}$ and 1.2 FSN at full load conditions [26]. In both dual-mode concepts, the major emissions reduction and efficiency gains come from the engine map region running under $\mathrm{RCCl}$ regime. By this reason, further studies are necessary to extend the limits of the concept to the major possible portion of the engine map.

The role of the low reactivity fuel properties over $\mathrm{RCCl}$ combustion has been widely investigated in literature [27]. The use of ethanol E85 allowed very high diesel fuel substitution rates, but increased $\mathrm{HC}$ and $\mathrm{CO}$ emissions dramatically [28]. The use of methanol as LRF promoted higher fuel efficiency than gasoline at some conditions. However, the combustion stability clearly worsened [29]. In this sense, using mid-level ethanol-gasoline blends as LRF was found a good compromise between emissions and performance as compared to using gasoline [30]. The influence of the LRF properties on $\mathrm{RCCl}$ was studied by modifying various operation parameters: the direct-injected fuel injection timing [31], in-cylinder charge temperature [32], composition [33] and premixed ratio [34], among others. Between them, the direct-injected fuel injection timing was found to be a key parameter [35]. In this sense, computational studies have shown that in-cylinder fuel stratification [36] must be optimized through the directinjected fuel injection timing variation in order to improving the gasoline burning around the critical regions of the combustion chamber, i.e., near the cylinder walls and crevice volumes [37]. From this, it can be inferred that the physical and chemical characteristics of the direct-injected fuel should also have an important role on the $\mathrm{RCCl}$ combustion process.

Considering this background, two main objectives were defined for the current investigation. The first one is to evaluate the operational limits of $\mathrm{RCCl}$ in a light-duty single-cylinder diesel engine using the stock compression ratio, 17.1:1. For this purpose, an engine mapping, following an experimental procedure defined and validated in previous works, was performed using diesel (D100) and gasoline (G100) as directinjected and port-injected fuels, respectively. The second objective is to study the effects of the direct-injected fuel properties on $\mathrm{RCCl}$ combustion. To do so, three additional fuels based on diesel-gasoline mixings at different ratios (D90, D70 and D50), also known as dieseline, were used as direct-injected fuel instead of D100. The RCCl combustion characteristics with the dieseline fuels were evaluated at the points that define the frontiers of maximum and minimum engine load of the baseline engine map (D100/G100).

\section{Materials and methods}

This section describes the main characteristics of the test cell used in this study, focusing on the engine unit and the different systems of which is equipped. Moreover, the main properties of the fuels used in the present investigation are detailed here. Finally, some 
considerations about the procedure followed during the experimental tests and the bases of the theoretical tool used to process the data acquired from the engine, are provided.

\subsection{Engine and fuels description}

The experiments were carried out on a light-duty, four stroke, single-cylinder diesel engine (SCE) based on a serial production $1.9 \mathrm{~L}$ platform. The engine has four valves driven by dual overhead cams and equips the serial production piston with re-entrant bowl, which confers a geometric compression ratio of 17.1:1. The SCE has two swirl valves (tangential and helical) in the intake port through which the swirl ratio can be varied from 0 to 5.2, as characterized in a cold flow test rig [38]. In this work, the position of both valves was fixed to give a constant swirl ratio of 1.4 during all the study, which is the lowest value that can be achieved with the stock engine configuration. The main characteristics of the engine are summarized in Table 1.

Table 1. Engine characteristics.

\begin{tabular}{|l|l|}
\hline Engine Type & 4 stroke, 4 valves, direct injection \\
\hline Number of cylinders [-] & 1 \\
\hline Displaced volume $\left[\mathrm{cm}^{3}\right]$ & 477 \\
\hline Stroke $[\mathrm{mm}]$ & 90.4 \\
\hline Bore $[\mathrm{mm}]$ & 82 \\
\hline Piston bowl geometry [-] & Re-entrant \\
\hline Compression ratio [-] & $17.1: 1$ \\
\hline Rated power [kW] & 27.5 @ 4000 rpm \\
\hline Rated torque $[\mathrm{Nm}]$ & 80 @ 2000-2750 rpm \\
\hline
\end{tabular}

The single-cylinder engine was installed in a test cell with the state-of-the-art subsystems needed for its operation and control. A scheme of the test cell is shown in Figure 1. The desired engine speed and load in the experiments were controlled by means of an electric dynamometer. A screw compressor capable of providing up to 3 bar was used to feed the engine with fresh air. Air relative humidity and temperature were regulated before entering into the intake settling chamber. This settling chamber was sized to attenuate the pulsating nature of the intake flow, thus ensuring a constant air supply to the engine. Pressure and temperature were monitored in the settling chamber for regulation purposes. A high-pressure EGR line was built to recirculate combustion products to the intake manifold. Thus, the intake charge pressure and temperature were monitored again in the intake manifold after the air-EGR mixing. The exhaust pressure and temperature were monitored in the exhaust manifold as well as in the exhaust settling chamber. The backpressure provoked by the turbocharger in the real multi-cylinder engine was reproduced during the experiments using a pneumatic valve. In this sense, the value set in the current experiments was taken from a CDC reference map performed on the same engine with the same instrumentation.

The in-cylinder pressure signal was acquired using a Kistler $6125 \mathrm{C}$ glow-plug piezoelectric transducer in series with a 4603B10 charge amplifier. 400 consecutive engine cycles were measured at each experimental point. The shaft encoder used provides 720 pulses per revolution, leading to a resolution of 0.5 crank angle (CA). However, a resolution of 0.2 CAD is achieved via interpolation. The pressure data were 
recorded using a Yokogawa DL708E with a 16 bits A/D converter module. The low frequency variables were acquired at a $100 \mathrm{~Hz}$ using an in-house developed recording system named SAMARUC. The gaseous engine-out emissions were measured with a five gas Horiba MEXA-7100 DEGR analyzer. The measurements for each steady state operating point were done over 60 seconds and repeated three times. Then, a mean value was calculated. The smoke emissions, in filter smoke number (FSN) units, were measured with an AVL $415 \mathrm{~S}$ smoke meter. In this sense, three consecutive measurements of 1 liter volume each with paper-saving mode off were acquired and averaged [39]. The accuracy of the main elements of the test cell is shown in Table 2.

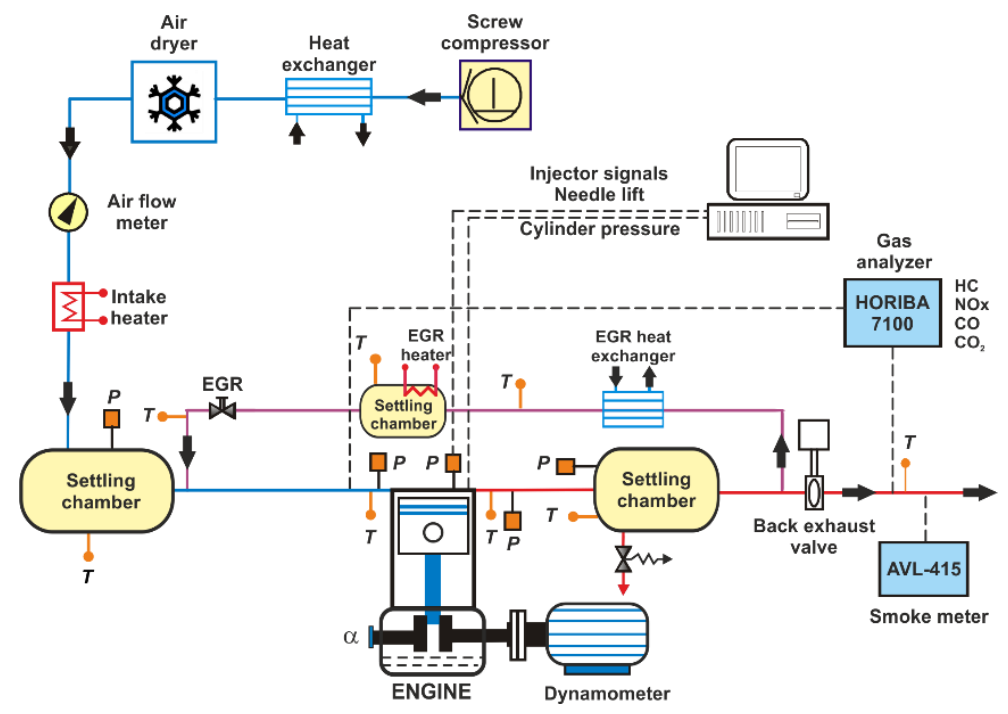

Figure 1. Test cell scheme.

Table 2. Accuracy of the instrumentation used in this work.

\begin{tabular}{|l|l|l|l|}
\hline Variable measured & Device & Manufacturer / model & Accuracy \\
\hline In-cylinder pressure & Piezoelectric transducer & Kistler / 6125BC & \pm 1.25 bar \\
\hline Intake/exhaust pressure & Piezorresistive transducers & Kistler / 4603B10 & \pm 25 mbar \\
\hline $\begin{array}{l}\text { Temperature in settling } \\
\text { chambers and manifolds }\end{array}$ & Thermocouple & TC direct / type K & $\pm 2.5{ }^{\circ} \mathrm{C}$ \\
\hline Crank angle, engine speed & Encoder & AVL / 364 & $\pm 0.02 \mathrm{CAD}$ \\
\hline $\mathrm{NOx}, \mathrm{CO}, \mathrm{HC}, \mathrm{O}_{2}, \mathrm{CO}_{2}$ & Gas analyzer & $\begin{array}{l}\mathrm{HORIBA} / \mathrm{MEXA} 7100 \\
\text { DEGR }\end{array}$ & $4 \%$ \\
\hline FSN & Smoke meter & AVL / 415 & $\pm 0.025 \mathrm{FSN}$ \\
\hline Gasoline/diesel fuel mass flow & Fuel balances & AVL / 733S & $\pm 0.2 \%$ \\
\hline Air mass flow & Air flow meter & Elster / RVG G100 & $\pm 0.1 \%$ \\
\hline
\end{tabular}

To allow RCCl operation, two fuel injection systems were built using commercial parts. The stock common-rail fuel injection system, with a centrally located solenoid injector, was used to introduce the direct-injected fuel into the cylinder. The injector control was handled through a DRIVVEN control system [40]. The port fuel injection (PFI) of the low reactivity fuel was done by means of a PFI located at the intake manifold, $160 \mathrm{~mm}$ far from the intake valves. The PFI command was done through a Genotec hardware. The PFI timing was set 10 CAD after the intake valve opening (IVO), as this timing showed a proper engine response in a preliminary study. DI and PFI mass flows were measured using dedicated AVL 733S fuel balances. The main characteristics of the DI and PFI as provided by the manufacturer are depicted in Table 3. 
Table 3. Characteristics of the direct and port fuel injector.

\begin{tabular}{|c|c|c|c|}
\hline \multicolumn{2}{|l|}{ Direct injector } & \multicolumn{2}{|l|}{ Port fuel injector } \\
\hline Actuation Type [-] & Solenoid & Injector Style [-] & Saturated \\
\hline Steady flow rate @ 100 bar $\left[\mathrm{cm}^{3} / \mathrm{min}\right]$ & 880 & Steady flow rate @ 3 bar $\left[\mathrm{cm}^{3} / \mathrm{min}\right]$ & 980 \\
\hline Included spray angle $\left[{ }^{\circ}\right]$ & 148 & Included Spray Angle $\left[{ }^{\circ}\right]$ & 30 \\
\hline Number of holes [-] & 7 & Injection Strategy [-] & single \\
\hline Hole diameter $[\mu \mathrm{m}]$ & 141 & Start of Injection [CAD ATDC] & 340 \\
\hline Maximum injection pressure [bar] & 1600 & Maximum injection pressure [bar] & 5.5 \\
\hline
\end{tabular}

Four direct-injected (DI) fuels were tested to evaluate the influence of their properties on $\mathrm{RCCl}$ performance and emissions. One of the fuels used was pure EN590 diesel (D100), while the other three are splash-blended mixtures of EN590 diesel and 98 octane number gasoline at different ratios: D90, D70 and D50, containing 10\%, 30\% and $50 \%$ of gasoline by volume, respectively. The fuel injected by the intake port was pure 98 octane number gasoline (G100), the same used to prepare the DI fuel blends. D100 and G100 were directly sourced from the petrol station. The main properties of the different fuels are summarized in Table 4. All the properties were obtained in the fuels laboratory at CMT-Motores Térmicos following the American society for testing and materials (ASTM) standards.

Table 4. Physical and chemical properties of the fuels.

\begin{tabular}{|l|c|c|c|c|c|}
\cline { 2 - 6 } \multicolumn{1}{c|}{} & D100 & D90 & D70 & D50 & G100 \\
\hline Density $\left[\mathrm{kg} / \mathrm{m}^{3}\right]\left(\mathrm{T}=15^{\circ} \mathrm{C}\right)$ & 842 & 833 & 816 & 800 & 747 \\
\hline Viscosity $\left[\mathrm{mm}^{2} / \mathrm{s}\right]\left(\mathrm{T}=40^{\circ} \mathrm{C}\right)$ & 2.929 & 2.325 & 1.422 & 0.981 & 0.545 \\
\hline RON $[-]$ & - & 72.67 & 63.22 & 53.78 & 97.6 \\
\hline MON [-] & - & 42.97 & 53.17 & 63.37 & 89.7 \\
\hline Cetane number [-] & 51 & 47.55 & 40.64 & 33.73 & - \\
\hline Lower heating value $[\mathrm{MJ} / \mathrm{kg}]$ & 42.50 & 42.66 & 42.98 & 43.3 & 44.09 \\
\hline
\end{tabular}

\subsection{In-cylinder pressure signal processing}

The in-cylinder pressure signal was processed using an in-house developed single-zone model named CALMEC [41]. For this purpose, CALMEC needs to be fed with different high and low frequency variables from the engine experiments such as the engine speed, inlet and exhaust temperatures from oil and coolant, air mass flow, EGR rate and fuel mass, and some others.

The combustion diagnosis tool is fed with the pressure traces of 400 consecutive engine cycles for each operating point, which leads to analyze the cycle-to-cycle variation. The individual raw pressure data is smoothed using a Fourier series low-pass filter. After that, the analysis is performed using a representative cylinder pressure trace obtained by averaging the collected cycles. Then, the first law of thermodynamics was applied between the intake valve closing (IVC) and exhaust valve opening (EVO), considering the combustion chamber as an open system because of the blow-by and fuel injection. The mean gas temperature in the chamber is calculated using the ideal gas equation of state. In addition, the gas thermodynamic conditions in the chamber are obtained through the in-cylinder pressure signal, and are used to feed the models used for estimating the 
convective and radiative heat transfer [42]. Moreover, the thermodynamic conditions are used as input for the filling-emptying model, which provides the fluid-dynamic conditions in the ports and the heat transfer flows in these elements. The wall temperatures are calculated by means of a lumped conductance model, which is connected to the heat transfer models.

The main results from CALMEC used in this investigation are the bulk gas temperature, maximum in-cylinder pressure $\left(P_{\max }\right)$ and maximum pressure rise rate (MPRR). Moreover, the rate of heat release (RoHR) and some parameters for describing the combustion process, such as the start of combustion (SOC) and the combustion phasing (CA50), are used. Thus, SOC and CA50 are defined as the crank angle in which the 5\% and $50 \%$ of the heat release is cumulated, respectively.

\subsection{Testing procedure}

The global procedure followed to perform the engine tests bases on three main steps, which are sketched in Figure 2. The first step consisted of performing a series of parametric sweeps of the main variables governing the in-cylinder reactivity, i.e., diesel start of injection (SOI), exhaust gas recirculation (EGR) rate and gasoline fraction (GF), defined as the ratio of gasoline mass over the total fuel, to limit their values to a certain range for the next steps. This task was done using diesel (D100) and gasoline (G100) as direct-injected and port-injected fuels, respectively. The single and couple effects of these variables have been widely explained in literature [43][44], so that this study is not included in the manuscript. However, it is interesting to note that this preliminary study revealed more potential with single than double injection strategy, so that this injection pattern was selected for the current study.

In the second step, a baseline engine mapping using D100 (DI) and G100 (PFI) was carried out following the experimental procedure described in previous works [21][24], which is summarized in Figure 2. The constraints imposed to perform the engine mapping were intended to achieve ultra-low emissions (ISNOx $<0.4 \mathrm{~g} / \mathrm{kWh}$, Smoke $<0.1 \mathrm{FSN}$ ) with acceptable combustion efficiency (ISCO $<5000 \mathrm{ppm}$ ), and without exceeding the engine mechanical limits (MPPR $<10$ bar/CAD and $P_{\max }<160$ bar). Methodologically, the final points of the engine map were reached by means of three consecutive steps, which are summarized in Figure 2. As the Figure 2 shows, the aim of the first step was to achieve stable $\mathrm{RCCl}$ operation (coefficient of variation, $\mathrm{COV}<4 \%$ ) through the gasoline fraction (GF) and diesel start of injection (SOI) modification, without taking care about the limitations imposed. In the next step, the EGR is also tuned to reduce the NOx and soot emissions levels down to the values imposed considering not to exceed the mechanical limits. At the same time, GF and diesel SOI are readjusted to improve the performanceemissions trade-off at this point. The last step consists of refining slightly the calibration in terms of EGR and diesel SOI to try to reduce the unburned products and the fuel consumption without exceeding the rest of the limitations.

Finally, to assess the influence of the direct-injected fuel properties on $\mathrm{RCCl}$ performance and emissions, the third step was divided into two sub-steps. Firstly, the operating points that define the frontiers of maximum and minimum engine load in the baseline engine map were reproduced for the different $\mathrm{DI}$ fuels using equal engine settings. In this way, the changes observed in the combustion process can be directly 
associated to the different DI fuel properties. Later, the engine settings were tuned for each DI fuel to accomplish the constrains imposed in the mapping procedure.

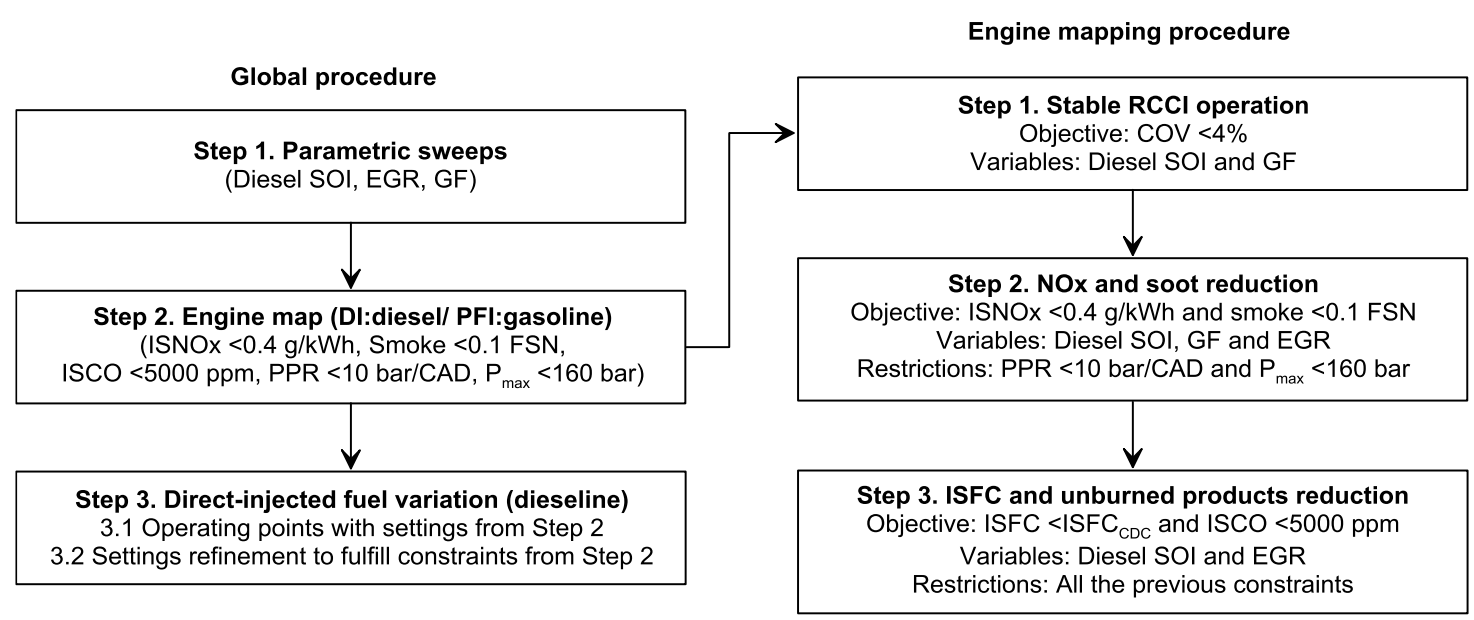

Figure 2. Global procedure followed during the experimental tests and engine mapping procedure description.

\section{Results and discussion}

This section contains the main results of the current investigation. The first subsection is dedicated to present the RCCl engine maps obtained using diesel (D100) and gasoline (G100) as high- and low-reactivity fuels, respectively. Later, the effects of the directinjected fuel properties on $\mathrm{RCCl}$ combustion characteristics are discussed.

\subsection{Reactivity controlled compression ignition mapping results}

A detailed description of the experimental procedure followed for mapping the engine is found in [21][24]. As summarized in Figure 2, this procedure proposes three steps before selecting an operating point as valid for the engine map: achieve stable $\mathrm{RCCl}$ operation ( $C O V_{\text {IMEP }}<4 \%$ ) with acceptable $P_{\max }$ and MPRR, tune the engine settings to achieve ultra-low NOx and smoke emissions simultaneously, and refine the engine settings for minimizing $\mathrm{CO}$ and $\mathrm{HC}$ levels without worsening the thermal efficiency. It is interesting to note that the injection pressure, intake pressure and temperature values used to obtain the maps were limited to be in the range of those used by the OEM in the calibration used for the serial-production diesel multi-cylinder engine.

Figure 3 shows the NOx and smoke emissions maps after applying the experimental procedure developed for the $\mathrm{RCCl}$ mapping. As it can be seen, the emissions levels are below the limits imposed for both pollutants (ISNOx $<0.4 \mathrm{~g} / \mathrm{kWh}$ and smoke $<0.1 \mathrm{FSN}$ ). The frontier of minimum engine load was limited by excessive $\mathrm{CO}$ emissions $(>5000$ ppm), while the maximum operable load was restricted by MPRR $>10$ bar/CAD (Figure 6). As seen in Figure 3, the highest NOx emissions rates are located on the line of the lowest load and at the high speed-high load portion of the map. At low load, the NOx emissions increase is explained by the low GF used, which promotes CA50 values in the range of -6 to -2 CAD ATDC (Figure 4). Thus, the relatively high diesel amount used, together with great part of the combustion period occurring during the compression stroke, favors the NOx formation due to the increase of the local in-cylinder temperatures. The high NOx emissions in the high load-high speed portion of the map 
are consequence of using a richer global air/fuel equivalence ratio (Figure 7) and a moderated EGR rate (Figure 5), which also lead to an increase of the flame temperature. Finally, the two peninsulas of lowest NOx emissions levels shown in the map are result of particular settings combinations in the calibration process. Smoke emissions are below $0.02 \mathrm{FSN}$ in the major portion of the engine map, only showing three peninsulas in which the smoke levels increase to near 0.04 FSN. The smoke levels at these points are consequence of particular engine settings combinations (i.e., the peninsula at low engine speed occurs due to using a delayed diesel SOI, low GF and high EGR).
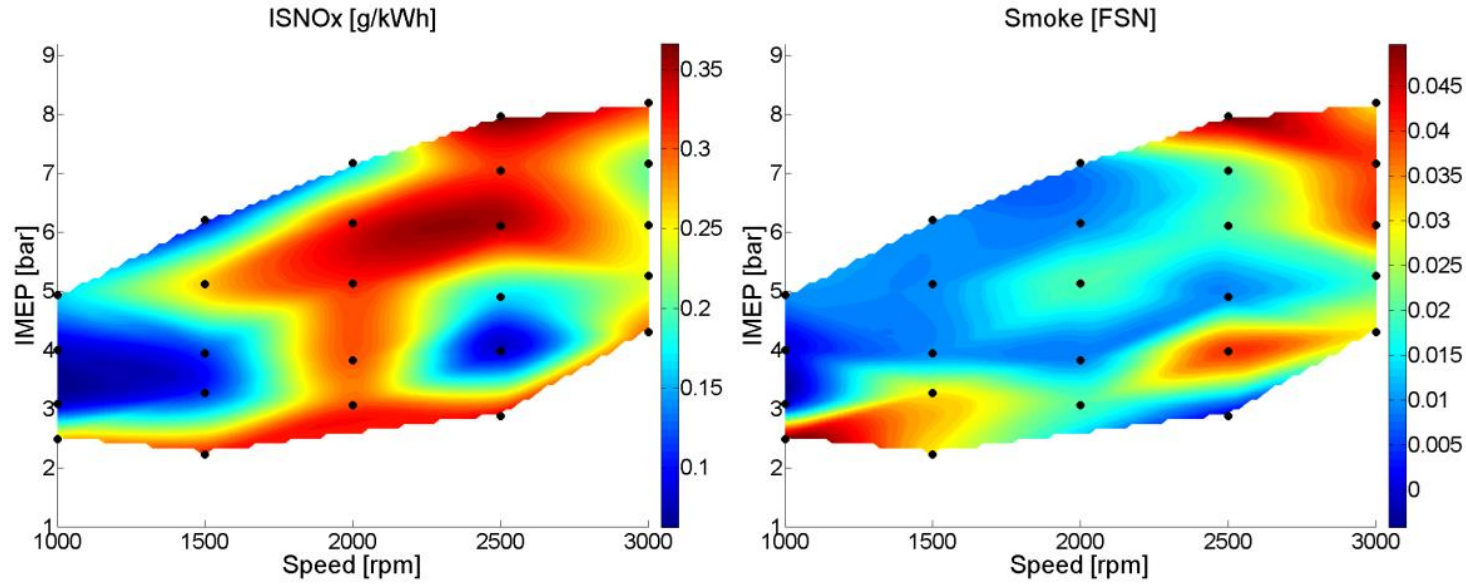

Figure 3. NOx and smoke emissions maps (DI:D100/ PFI:G100).
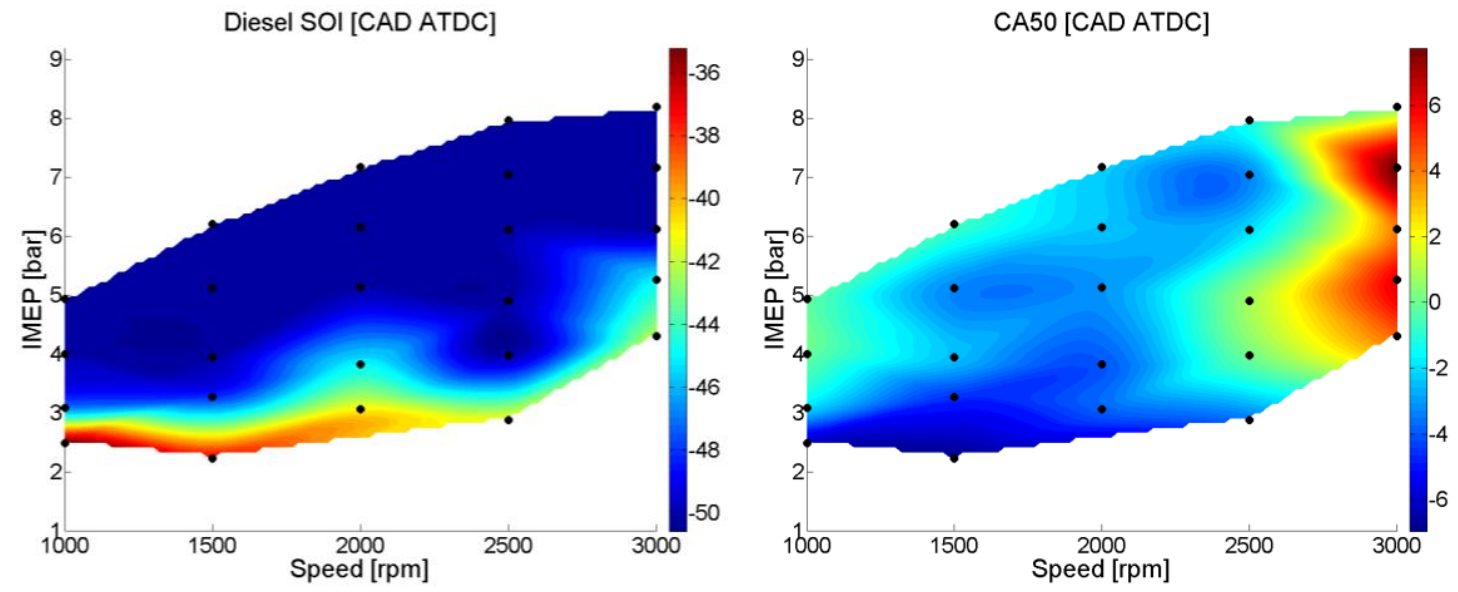

Figure 4. Diesel SOI and CA50 maps (DI:D100/ PFI:G100). 

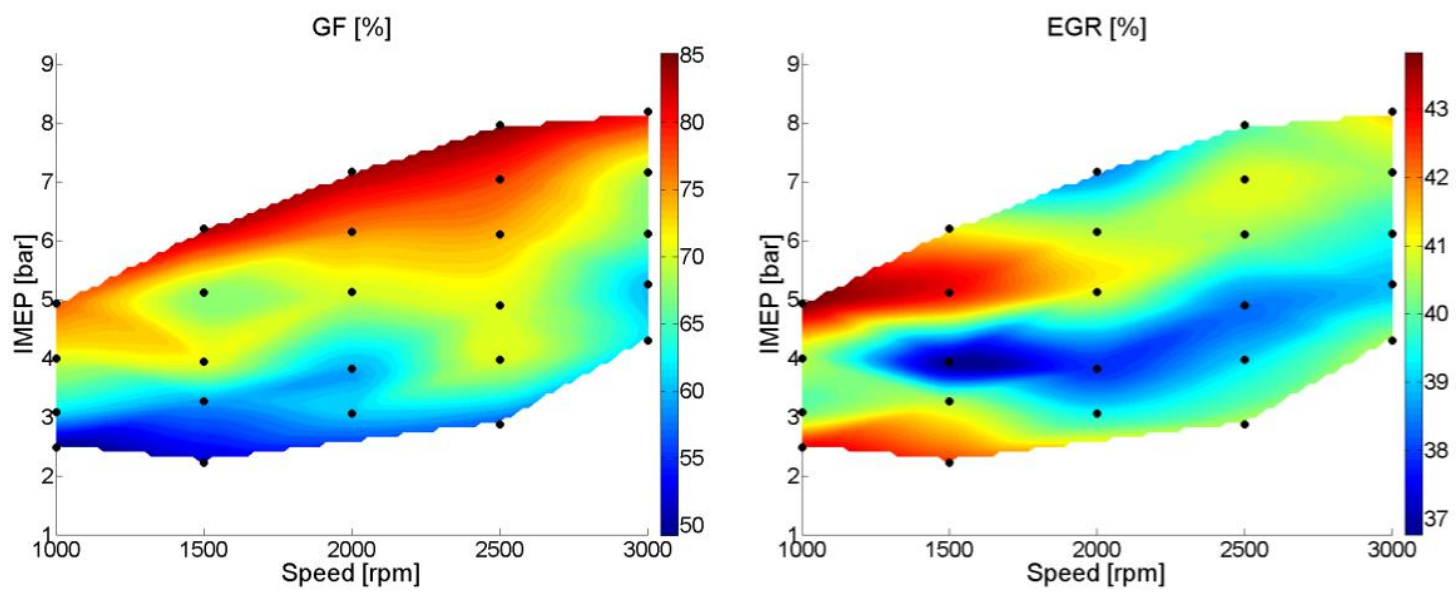

Figure 5. GF and EGR rate maps (DI:D100/ PFI:G100).

Figure 6 shows the MPRR and $P_{\max }$ maps. As it can be seen, both parameters increase with the engine load. This is mainly consequence of the change in the burning behavior from low to high load. At low load, the low-reactive in-cylinder conditions lead to a soft heat realease, with pressure gradients in the range of 3-5 bar/CAD and in-cylinder pressure peaks below 90 bar. At high load, richer global air/fuel equivalence ratios (Figure 7) and moderated EGR rates (Figure 5) are used. At these conditions, and considering the high compression ratio of the engine used, gasoline is more prone to burn than at low load. Therefore, a fast heat release with high MPRR and $P_{\max }$ peaks is obtained after the first combustion reactions, leading to the NOx emissions increase observed in Figure 3. As commented before, the maximum operable load was limited by excessive maximum pressure gradients (MPRR $>10$ bar/CAD), while the maximum incylinder pressure peaks were found to be lower than 160 bar along the entire map.
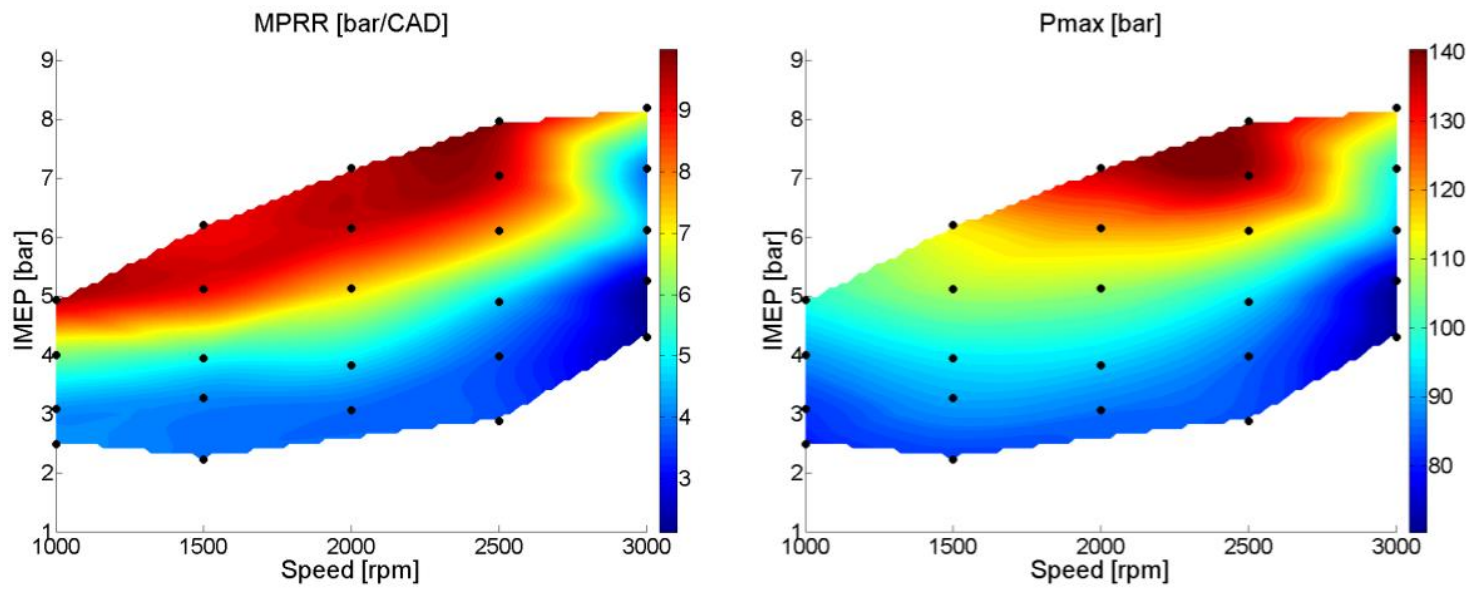

Figure 6. MPRR and $P_{\max }$ maps (DI:D100/ PFI:G100).

Figure 7 shows the $\mathrm{HC}$ and $\mathrm{CO}$ emissions maps. As it can be seen, both emissions are higher in the low load region of the map, being more critical at low engine speed conditions. Looking at Figure 8 , it can be inferred that this behavior should be consequence of the air/fuel mixture over-dilution due to the very lean global air/fuel equivalence ratios used. This fact, together with the low in-cylinder pressure and temperature experienced at low load, leads to a poor burning of the homogeneously mixed gasoline. As load increases, MPRR, $\mathrm{P}_{\max }$ and bulk gas temperature increase, reducing the $\mathrm{HC}$ and $\mathrm{CO}$ levels below 8 and $10 \mathrm{~g} / \mathrm{kWh}$, respectively. 
The air/fuel mixture over-dilution phenomenon was tried to be avoided by delaying the diesel start of injection (Figure 4) as much as possible, up to the point in which the NOx and/or smoke emissions were excessive due to the appearance of local rich air/fuel equivalence ratios. Even in this case, bulk combustion temperatures at low load conditions were low, leading to high levels of $\mathrm{HC}$ and $\mathrm{CO}$ emissions. As load increases, the diesel SOI is advanced, which allows the diesel fuel arriving to the critical regions of the combustion chamber, i.e., near the cylinder walls and crevice volumes, therefore improving the gasoline burning at these regions [45]. Moreover, the modification of the injection parameters are expected to cause changes in the combustion regimes, also having an impact on the engine-out emissions.
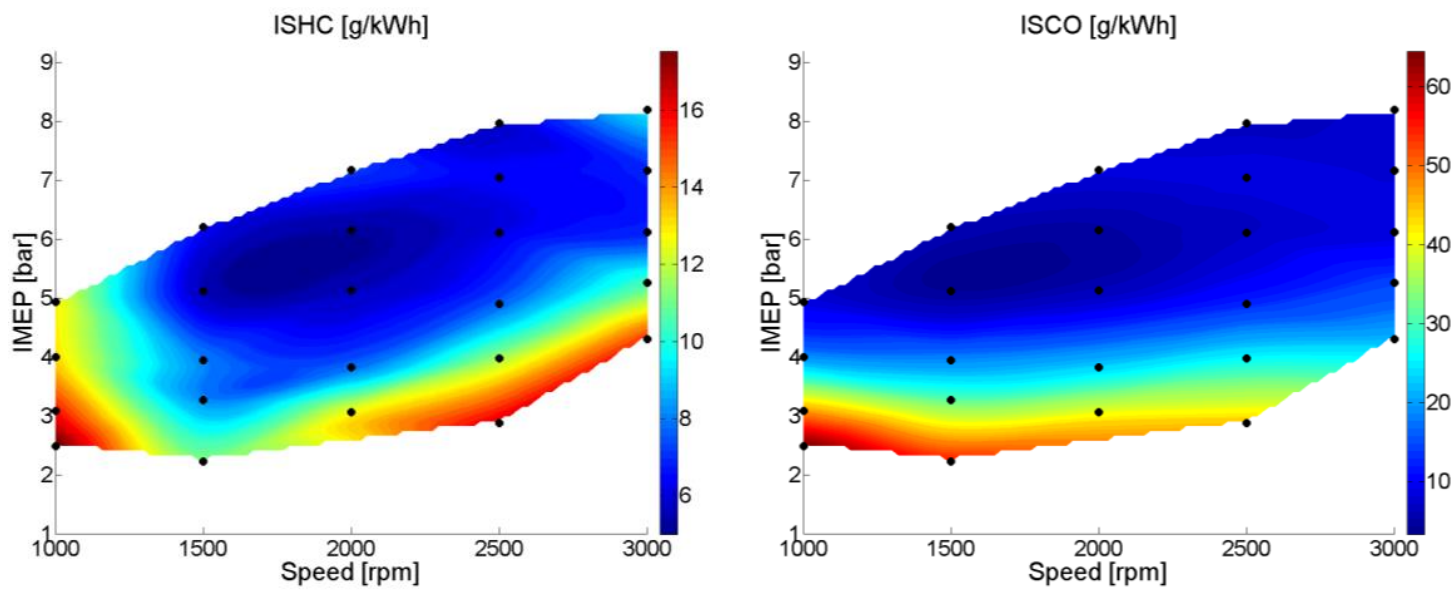

Figure 7. HC and CO emissions maps (DI:D100/ PFI:G100).
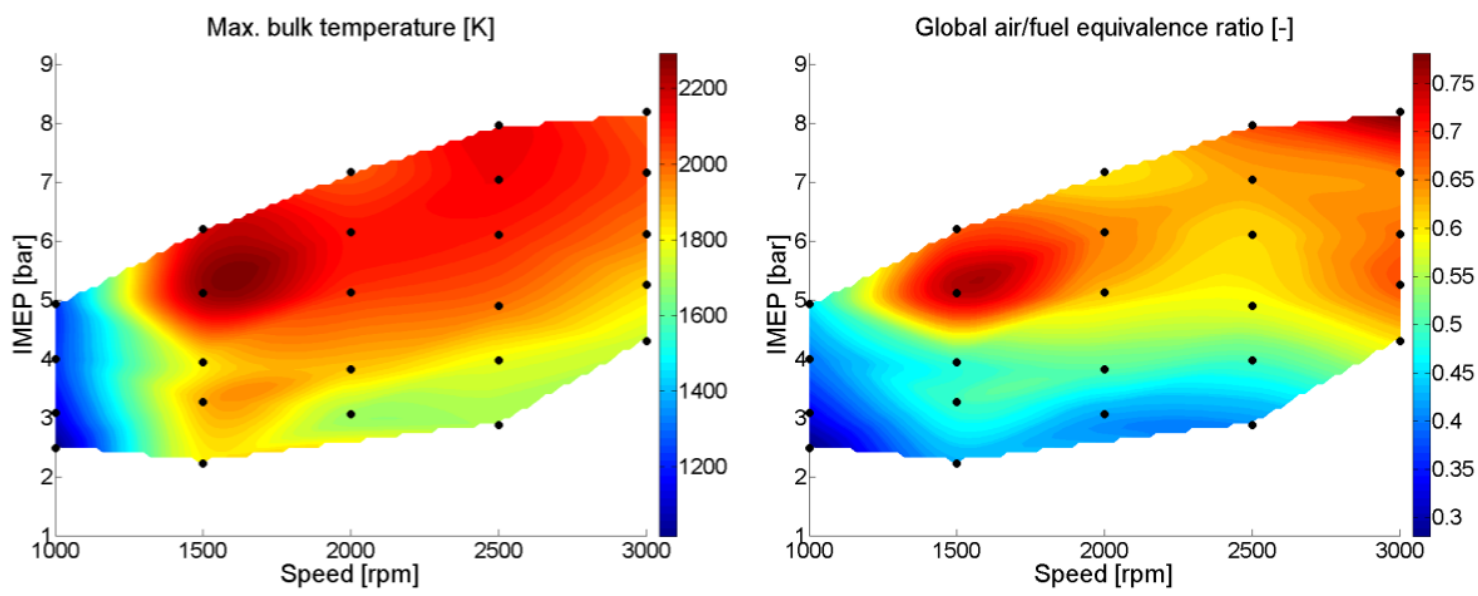

Figure 8. Maximum bulk gas temperature and global air/fuel equivalence ratio maps (DI:D100/ PFI:G100).

\subsection{Effects of direct-injected fuel properties on reactivity controlled compression ignition combustion characteristics}

The effects of the direct-injected fuel properties have been evaluated at the points that define the frontiers of maximum and minimum engine load in the baseline engine map (D100/G100). As a first approach, the engine settings (GF, diesel SOI, diesel mass, total 
fuel mass, EGR, intake pressure and temperature, exhaust pressure...) were not varied to isolate the effects of each DI fuel. To keep constant the diesel and total mass and the global GF when comparing between fuels, the PFI gasoline mass had to be adjusted. In this sense, the PFI gasoline mass was reduced at same proportion than the DI gasoline amount increased when moving from D100 to D50. As a result, the premixed ratio decreased. Finally, in the cases that was necessary, the engine settings were slightly refined following the experimental procedure described in section 2.3 to accomplish the emissions and mechanical constrains imposed in the engine mapping procedure.

Figure 9 shows the RoHR for the different DI fuels at the points that define the frontiers of minimum and maximum load in the baseline engine map. Two different behaviors can be confirmed by comparing the RoHR profiles at the extremes of the speed range (1000 and $3000 \mathrm{rpm}$ ) versus the other engine speeds. At $1000 \mathrm{rpm}$, all the fuels show less energetic heat release rates than at other engine speed. This occurs due to the notably lower global equivalence ratio ( $\Phi \approx 0.25$ vs $\Phi \approx 0.4-0.6$ ), which worsens the combustion propagation. At $3000 \mathrm{rpm}$, this behavior also appears for the fuels with lower reactivity (D70 and D50) due to the lower time available for combustion. The comparison between fuels at these two operating points reveals that the rate of heat release curves corresponding to the direct-injected fuel with lowest reactivity (D50) show more delayed start of combustion and lower heat release peaks. This occurs because as the direct-injected gasoline increases, the premixed equivalence ratio reduces to maintain constant the global GF. For D50, the premixed equivalence ratio is 0.11 at $1000 \mathrm{rpm}(\Phi \approx 0.15$ for other fuels) and 0.23 at $3000 \mathrm{rpm}(\Phi \approx 0.37$ for other fuels), which worsens the combustion propagation. This trend between fuels is also observed in the points that define the high load frontier.

For the intermediate engine speed levels (1500, 2000 and $2500 \mathrm{rpm})$, the rate of heat release curves of D50 show a more spiky profile, with shorter duration, greater peaks and slightly delayed start of combustion. These results evidence that, as the reactivity gradient between the high and low reactivity fuel diminishes, the sequential autoignition achieved in $\mathrm{RCCl}$ due to local combustion reactions switches to a more kinetically controlled $\mathrm{HCCl}$-like combustion process [46]. 

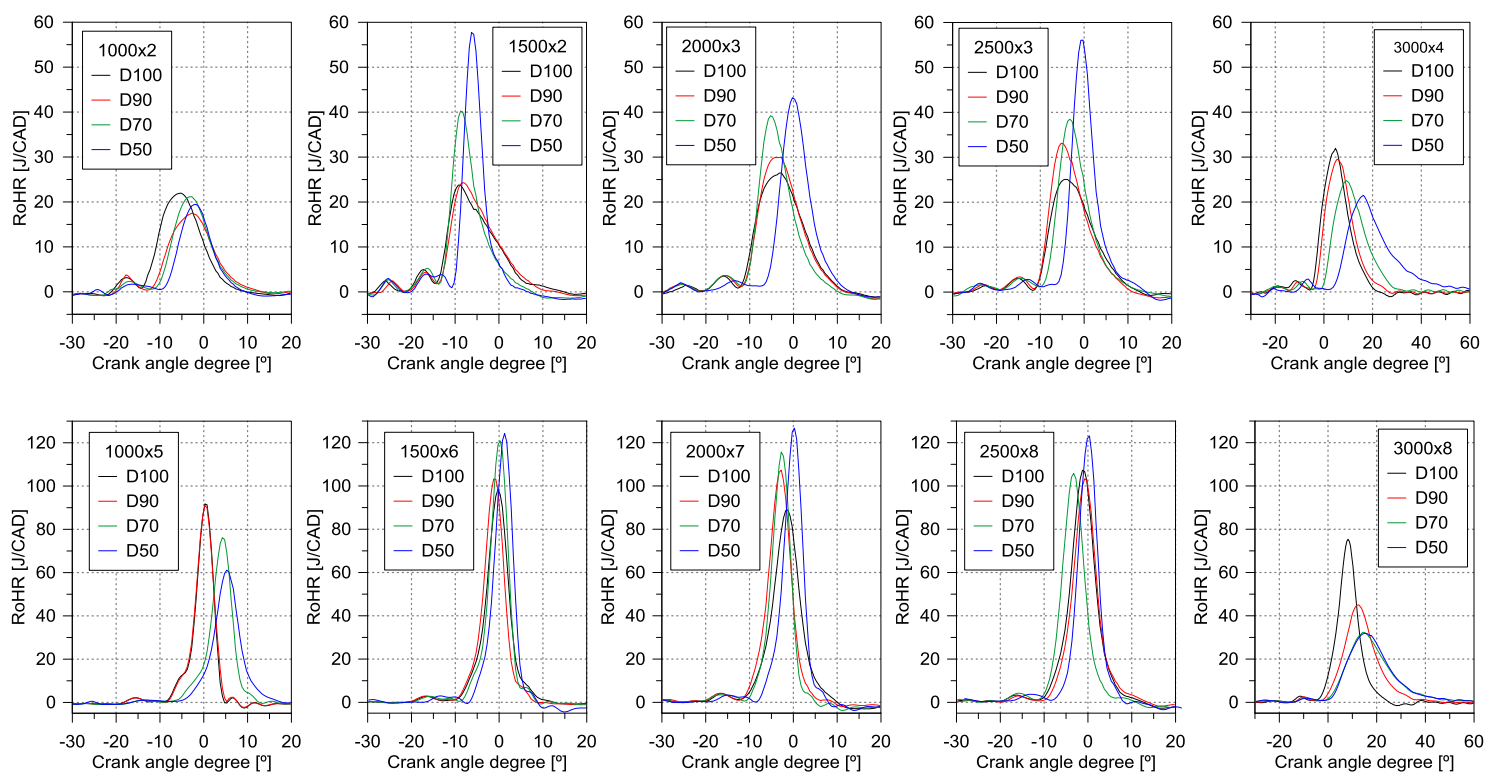

Figure 9. RoHR for the different DI fuels at the points that define the frontiers of minimum (top) and maximum (bottom) load in the baseline engine map. The engine settings at a given operating point are equal for all the fuels.

Figure 10 shows the engine-out emissions and gross indicated efficiency (GIE) for the points shown in Figure 9. The maximum pressure rise rate was below 10 bar/CAD in all the cases. From Figure 10, it is seen that smoke emissions are very low for all the fuels, showing values below 0.05 FSN whatever the engine speed and load considered. Hydrocarbons emissions show a U-shaped trend in both subfigures included in Figure 10 , which is clearer as the direct-injected fuel reactivity decreases. However, the flat part of the curve shows lower emissions levels for the fuels of lower reactivity, which is coherent with the RoHR behavior described before. At low load, CO emissions at 1000 rpm are very high due to the low global equivalence ratio used, being the levels for the dieseline blends unacceptable. At other engine speeds, $\mathrm{CO}$ emissions show a flat profile at $40 \mathrm{~g} / \mathrm{kWh}$. CO emissions levels are much lower at the highest load, which is expected considering the maximum RoHR peaks shown in Figure 9. Maximum $\mathrm{CO}$ values between 20-30 g/kWh are found at the extreme speeds for D50, while the levels in the flat part of the curve are $10 \mathrm{~g} / \mathrm{kWh}$, four time less than at low load.

At low load, NOx emissions are below $0.4 \mathrm{~g} / \mathrm{kWh}$ for all the engine speeds only in the case of D100. D70 and D50 only fulfill this limitation at the extreme of the speed range, where combustion efficiency was found to be low (high HC and CO). D90 only shows one point above the limit, at $2500 \mathrm{rpm}$. These results are coherent attending to the combustion process evolution shown in Figure 9, where the higher ROHR peaks promote greater in-cylinder temperatures during combustion. At high load, D100 and D90 show NOx emissions levels under the limit imposed whatever the engine speed. By contrast, as showed at low load, the two fuels with lowest reactivity will need a recalibration to fulfil the limit proposed due to the appearance of a more $\mathrm{HCCl}-$ like combustion event.

Finally, the GIE analysis at low load reveals that, at $1000 \mathrm{rpm}$, GIE decreases as the gasoline direct-injected portion increases, which was remarked during the RoHR analysis. As engine speed increases, GIE for D70, D90 and D100 is almost identical, showing an increasing trend with the engine speed. In the case of $3000 \mathrm{rpm}$, the GIE for all fuels is maximum even considering the not so big RoHR because of the better 
combustion phasing (CA50 ranging from +4 to +9 CAD ATDC), which enhances the fuelto-work conversion efficiency. The Figure 10 (left) also shows a singular behavior of the GIE with D50, showing higher sensitivity to the engine speed than the rest of the fuels tests. In this sense, $\mathrm{RCCl}$ combustion with D50 seems to be more dependent to incylinder conditions due to the less reactivity gradient between the high and low reactivity fuels. As shown in the Figure 10 (left), GIE for D50 at 1500, 2000 and 2500 rpm is higher than D100. However, NOx emissions are out of the limit imposed. Finally, at high load, only substantial differences are seen at 1500 and $3000 \mathrm{rpm}$, where all the dieseline blends perform worse than D100.
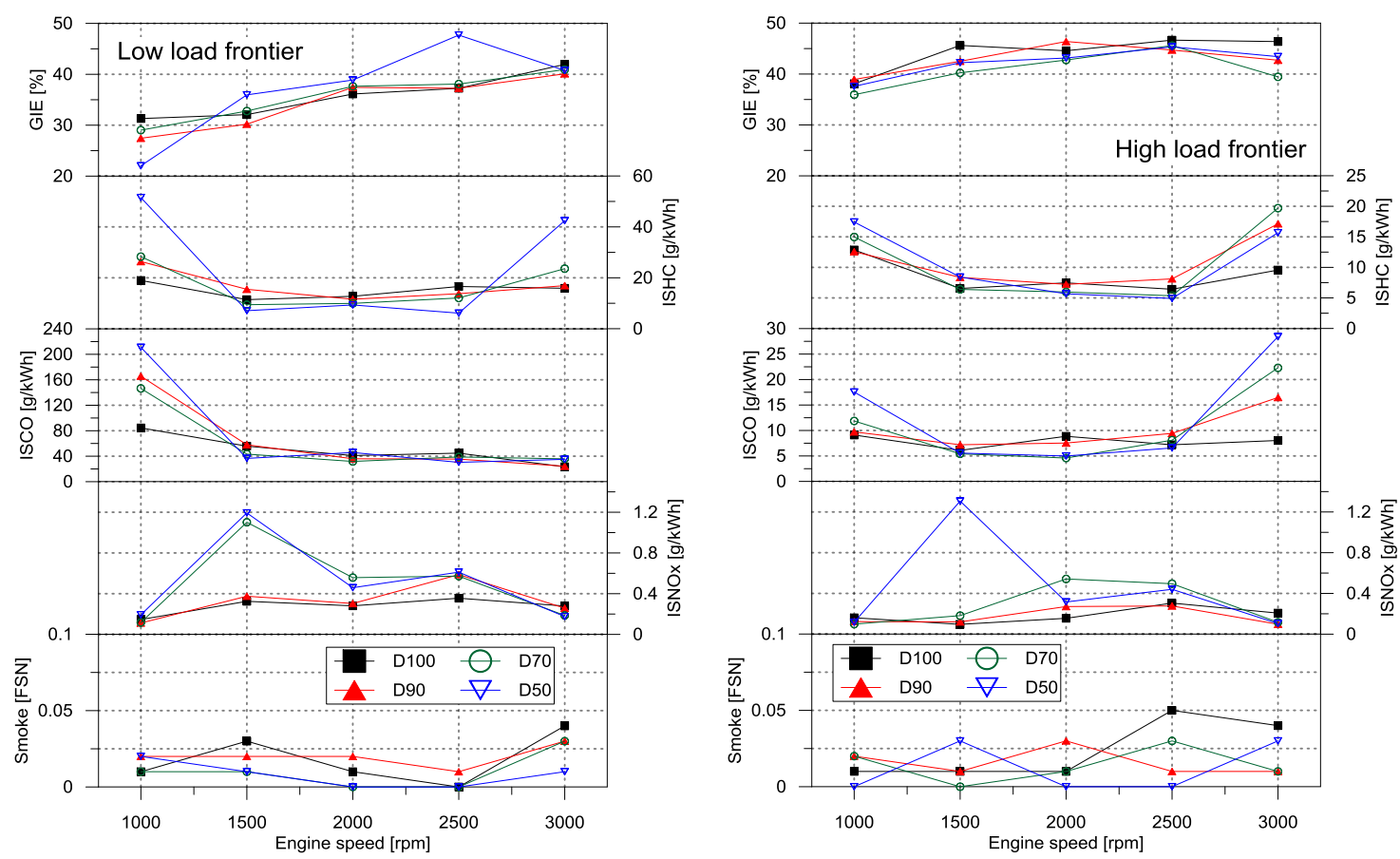

Figure 10. Engine-out emissions and GIE for the different DI fuels at the points that define the frontiers of minimum (left) and maximum (right) load in the baseline engine map. The engine settings at a given operating point are equal for all the fuels.

Figure 11 shows the engine-out emissions and gross indicated efficiency (GIE) for the different DI fuels after refining the engine settings at the points that exceeded the emissions and/or mechanical limits. The points for the three dieseline blends (D90, D70 and D50) have been reached taking as a base the points performed at iso-settings and slightly modifying some calibration parameters following the experimental procedure described in section 2.3. This method does not represent an optimal calibration for efficiency or emissions but rather a compromise between the two to assess the capability of each DI fuel to perform inside the boundaries imposed. A dedicated optimization will be done in future steps of the research.

From Figure 11 it is seen that, under conditions tested, all the DI fuels allow achieving the mapping constraints at the points that define the frontiers of minimum and maximum load of the baseline map. In terms of engine-out emissions, the dieseline blends show no clear potential versus using D100 as direct-injected fuel. In this sense, smoke emissions are negligible for all fuels, but NOx emissions from dieseline fuels are nearer the limit imposed at both loads. Moreover, $\mathrm{HC}$ and $\mathrm{CO}$ emissions form dieseline blends are equal or slightly higher than D100 in almost all cases. Only D50 shows a 
consistent reduction of $\mathrm{HC}$ and $\mathrm{CO}$ levels from 2000 to $3000 \mathrm{rpm}$ at both loads. Regarding GIE, in general terms, D90 performs similar to D100 at both load levels. D70 performs slightly worse at low engine speeds and similarly as the engine speed increases. Finally, D50 shows a clear worsen in GIE at the lower engine speeds and clear benefit at the higher engine speeds. At high load, D50 shows identical behavior compared with D100, but improving the performance at the highest engine speed.
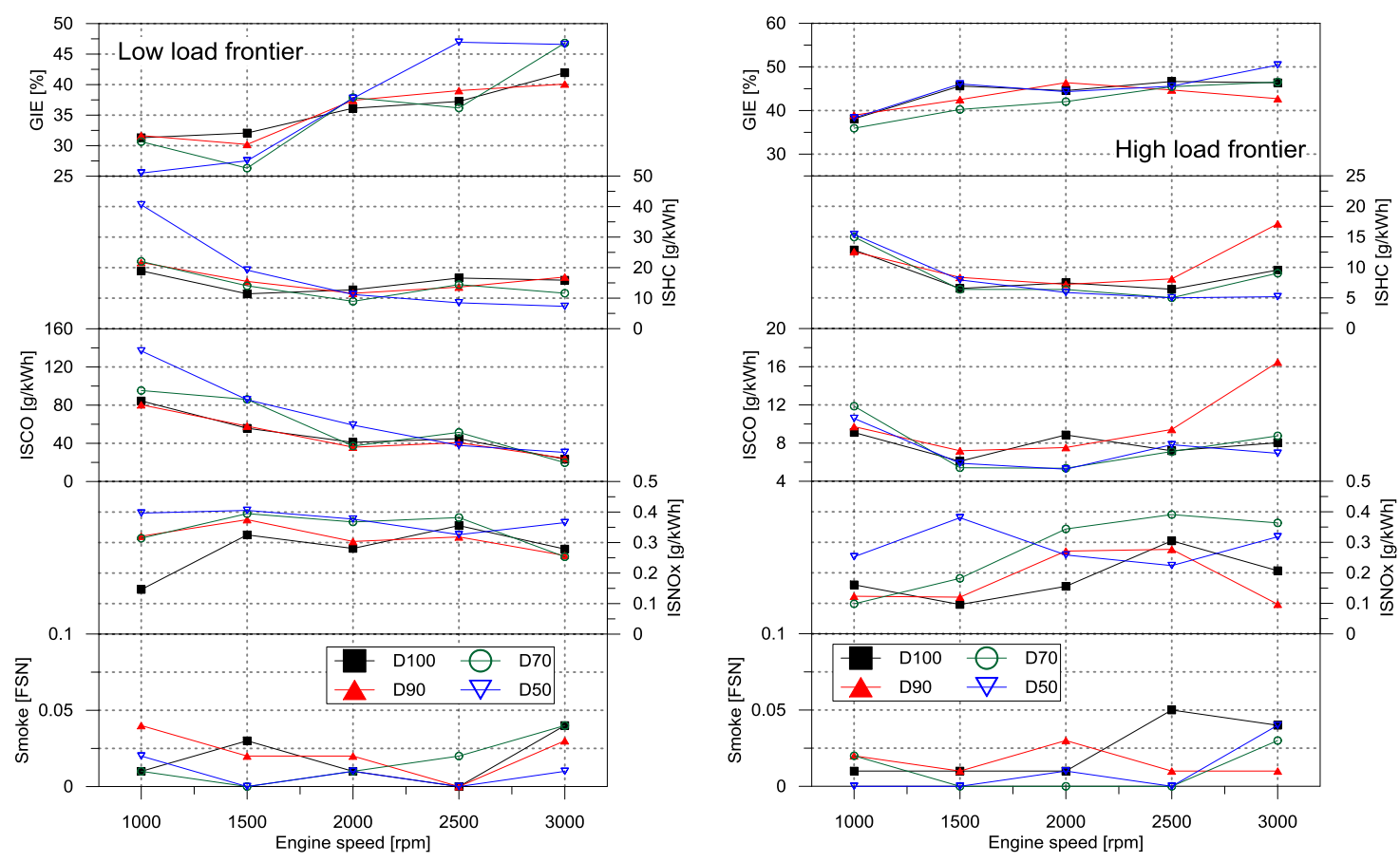

Figure 11. Engine-out emissions and GIE for the different DI fuels after refining the engine settings at the points that exceeded the emissions/mechanical limits. The operating points that define the frontiers of minimum (left) and maximum (right) load are shown.

\section{Conclusions}

This work has investigated experimentally the operational limits of $\mathrm{RCCl}$ concept in a high compression ratio light-duty single-cylinder diesel engine with specific constraints. In addition, the effects of using different direct-injected fuels on engine-out emissions and performance have been analyzed.

Under the conditions tested, which correspond to using injection pressure, intake pressure and intake temperature values typical of the standard light-duty $\mathrm{Cl}$ engines, the operational limits of the RCCl concept using diesel (D100) and gasoline (G100) as directinjected and port-injected fuels, respectively, have been found to be confined in the region defined from 2 to 5 bar IMEP at $1000 \mathrm{rpm}$ and from 4 to 8 bar IMEP at $3000 \mathrm{rpm}$. In that portion of the map, nitrogen oxides and smoke emissions were below $0.4 \mathrm{~g} / \mathrm{kWh}$ and 0.1 FSN simultaneously, and the engine mechanical limits were respected.

The effects of the direct-injected fuel properties were evaluated at the points that define the frontiers of maximum and minimum engine load in the baseline engine map (D100/G100). In particular, three dieseline blends (D90, D70 and D50) were tested as direct-injected fuels with the same engine settings than for D100. The combustion analysis showed that, as the reactivity gradient between the HRF and LRF diminishes (i.e., gasoline portion in the HRF increases), the sequential autoignition achieved in RCCI 
due to local combustion reactions switches to a more kinetically controlled $\mathrm{HCCl}$-like combustion process. This promotes higher NOx emissions as a general trend. Finally, all the fuels were found to be capable of operating inside the emissions restrictions imposed by doing little modifications on the baseline calibration. However, no clear potential was found in using dieseline blends as high-reactivity fuel rather than using pure diesel.

\section{Acknowledgments}

The authors gratefully acknowledge General Motors Global Research \& Development for providing the engine used in this investigation. The authors also acknowledge FEDER and Spanish Ministerio de Economía y Competitividad for partially supporting this research through HiReCo project (TRA2014-58870-R). The author J. Monsalve-Serrano acknowledges the financial support from the Universitat Politècnica de València under the grant "Ayudas Para la Contratación de Doctores para el Acceso al Sistema Español de Ciencia, Tecnología e Innovación".

\section{References}

[1] Kokjohn S L, Hanson R M, Splitter D A, Reitz R D. Fuel reactivity controlled compression ignition (RCCl): a pathway to controlled high-efficiency clean combustion, International Journal of Engine Research, 2011. Volume 12, June 2011, Pages 209-226.

[2] Benajes J, García A, Monsalve-Serrano J, Balloul I, Pradel G. Evaluating the reactivity controlled compression ignition operating range limits in a high-compression ratio medium-duty diesel engine fueled with biodiesel and ethanol. International Journal of Engine Research, Volume 18 (1-2), Pages 66-80, 2017.

[3] García-Valladolid P, Tunestal P, Monsalve-Serrano J, García A, Hyvönen J. Impact of diesel pilot distribution on the ignition process of a dual fuel medium speed marine engine. Energy Conversion and Management, Volume 149, 1 Oct 2017, Pages 192205.

[4] Yang B, Yao M, Cheng W, Li Y, Zheng Z, Li S. Experimental and numerical study on different dual-fuel combustion modes fuelled with gasoline and diesel. Applied Energy, 113 (2014), pp. 722-733.

[5] Park S, Shin D, Park J. Effect of ethanol fraction on the combustion and emission characteristics of a dimethyl ether-ethanol dual-fuel reactivity controlled compression ignition engine. Applied Energy, Volume 182, November 2016, Pages 243-252.

[6] Benajes J, Pastor JV, García A, Boronat V. A RCCI operational limits assessment in a medium duty compression ignition engine using an adapted compression ratio. Energy Conversion and Management, Volume 126, 2016, Pages 497-508.

[7] García A, Monsalve-Serrano J, Rückert Roso V, Santos Martins M. Evaluating the emissions and performance of two dual-mode RCCl combustion strategies under the World Harmonized Vehicle Cycle (WHVC). Energy Conversion and Management, Volume 149, 1 Oct 2017, Pages 263-274.

[8] Garcia A, Monsalve-Serrano J, Heuser B, Jakob M, Kremer F, Pischinger S. Influence of fuel properties on fundamental spray characteristics and soot emissions using different tailor-made fuels from biomass. Energy Conversion and Management, Volume 108, 15 January 2016, Pages 243-254. 
[9] Splitter D, Wissink M, DelVescovo D, Reitz R. RCCI Engine Operation Towards 60\% Thermal Efficiency. SAE Technical Paper 2013-01-0279, 2013, doi:10.4271/2013-010279.

[10] Shi L, Deng K, Cui Y, Qu S, Hu W. Study on knocking combustion in a diesel $\mathrm{HCCl}$ engine with fuel injection in negative valve overlap. Fuel, Volume 106, April 2013, Pages 478-483.

[11] Jain A, Singh A, Agarwal A. Effect of fuel injection parameters on combustion stability and emissions of a mineral diesel fueled partially premixed charge compression ignition (PCCl) engine. Applied Energy, Volume 190, 15 March 2017, Pages 658-669.

[12] Leermakers C, Bakker P, Nijssen B, Somers L, Johansson B. Low octane fuel composition effects on the load range capability of partially premixed combustion. Fuel, Volume 135, 1 November 2014, Pages 210-222.

[13] Benajes J, Molina S, García A, Monsalve-Serrano J, Durrett R. Conceptual model description of the double injection strategy applied to the gasoline partially premixed compression ignition combustion concept with spark assistance. Applied Energy, Volume 129, 15 September 2014, Pages 1-9.

[14] Benajes J, García A, Tormos B, Monsalve-Serrano J. Impact of Spark Assistance and Multiple Injections on Gasoline PPC Light Load. SAE International Journal of Engines 7(4):2014, doi:10.4271/2014-01-2669.

[15] Benajes J, García A, Pastor JM, Monsalve-Serrano J. Effects of piston bowl geometry on Reactivity Controlled Compression Ignition heat transfer and combustion losses at different engine loads. Energy, Volume 98, March 2016, Pages 64-77.

[16] Li J, Yang W, Goh T, An H, Maghbouli A. Study on RCCl (reactivity controlled compression ignition) engine by means of statistical experimental design. Energy, 78 (2014), pp. 777-787.

[17] Benajes J, Pastor JV, García A, Monsalve-Serrano J. The potential of RCCI concept to meet EURO VI NOx limitation and ultra-low soot emissions in a heavy-duty engine over the whole engine map. Fuel, Volume 159, November 2015, Pages 952-961.

[18] Benajes J, García A, Monsalve-Serrano J, Boronat V. Dual-Fuel Combustion for Future Clean and Efficient Compression Ignition Engines. Applied Sciences 7(1):36, 2017.

[19] Li J, Yang W, Zhou D. Review on the management of RCCl engines. Renewable and Sustainable Energy Reviews, Volume 69, March 2017, Pages 65-79.

[20] Yang Y, Dec J, Dronniou N, Sjöberg M. Tailoring $\mathrm{HCCl}$ heat-release rates with partial fuel stratification: Comparison of two-stage and single-stage-ignition fuels. Proceedings of the Combustion Institute, Volume 33 (2), pp. 3047-3055, 2011.

[21] Curran S, Gao Z, Wagner R. Reactivity Controlled Compression Ignition Drive Cycle Emissions and Fuel Economy Estimations Using Vehicle Systems Simulations with E30 and ULSD. SAE International Journal of Engines 7(2):2014, doi:10.4271/2014-01-1324.

[22] Curran S, Hanson R, Wagner R. Reactivity controlled compression ignition combustion on a multi-cylinder light-duty diesel engine. International Journal of Engine Research 13 (3), 216-225. 
[23] Benajes J, García A, Monsalve-Serrano J, Boronat V. Achieving clean and efficient engine operation up to full load by combining optimized $\mathrm{RCCl}$ and dual-fuel dieselgasoline combustion strategies. Energy Conversion and Management, Volume 136, 15 March 2017, Pages 142-151.

[24] Benajes J, García A, Monsalve-Serrano J, Balloul I, Pradel G. An assessment of the dual-mode reactivity controlled compression ignition/conventional diesel combustion capabilities in a EURO VI medium-duty diesel engine fueled with an intermediate ethanol-gasoline blend and biodiesel. Energy Conversion and Management, Volume 123, July 2016, Pages 381-391.

[25] Benajes J, García A, Monsalve-Serrano J, Boronat V. An investigation on the particulate number and size distributions over the whole engine map from an optimized combustion strategy combining RCCl and dual-fuel diesel-gasoline. Energy Conversion and Management, Volume 140, 15 May 2017, Pages 98-108.

[26] Benajes J, García A, Monsalve-Serrano J, Boronat V. Gaseous emissions and particle size distribution of dual-mode dual-fuel diesel-gasoline concept from low to full load. Applied Thermal Engineering, Volume 120, 25 Jun 2017, Pages 138-149.

[27] Benajes J, Molina S, García A, Monsalve-Serrano J. Effects of low reactivity fuel characteristics and blending ratio on low load $\mathrm{RCCl}$ (reactivity controlled compression ignition) performance and emissions in a heavy-duty diesel engine. Energy, Volume 90, October 2015, Pages 1261-1271.

[28] Sarjovaara T, Larmi M. Dual fuel diesel combustion with an E85 ethanol/gasoline blend. Fuel, 139 (2015), pp. 704-714.

[29] Li Y, Jia M, Chang Y, Xie M, Reitz R. Towards a comprehensive understanding of the influence of fuel properties on the combustion characteristics of a $\mathrm{RCCl}$ (reactivity controlled compression ignition) engine. Energy, Volume 99, March 2016, Pages 69-82.

[30] Benajes J, Molina S, García A, Monsalve-Serrano J. Effects of Direct injection timing and Blending Ratio on RCCl combustion with different Low Reactivity Fuels. Energy Conversion and Management, Volume 99, July 2015, Pages 193-209.

[31] Ma S, Zheng Z, Liu H, Zhang Q, Yao M. Experimental investigation of the effects of diesel injection strategy on gasoline/diesel dual-fuel combustion. Applied Energy, Vol. 109, pp 202-212, 2013.

[32] Sarjovaara T, Larmi M, Vuorinen V. Effect of charge air temperature on E85 dualfuel diesel combustion. Fuel, Vol. 153, pp. 6-12, 2015.

[33] Desantes JM, Benajes J, García A, Monsalve-Serrano J. The Role of the In-Cylinder Gas Temperature and Oxygen Concentration over Low Load RCCI Combustion Efficiency. Energy, Volume 78, December 2014, Pages 854-868.

[34] Wei L, Yao C, Wang Q, Pan W, Han G. Combustion and emission characteristics of a turbocharged diesel engine using high premixed ratio of methanol and diesel fuel. Fuel, 140 (2015), pp. 156-163.

[35] Nazemi M, Shahbakhti M. Modeling and analysis of fuel injection parameters for combustion and performance of an RCCl engine. Applied Energy, Vol. 165, pp 135150, 2016. 
[36] Kokjohn S, Reitz R, Splitter D, Musculus M. Investigation of fuel reactivity stratification for controlling $\mathrm{PCl}$ heat-release rates using high-speed chemiluminescence imaging and fuel tracer fluorescence. SAE Technical Paper (2012) 2012-01-0375.

[37] Kokjohn S L, Hanson R M, Splitter D A, Reitz R D. Fuel reactivity controlled compression ignition (RCCl): a pathway to controlled high-efficiency clean combustion, International Journal of Engine Research, 2011. Volume 12, June 2011, Pages 209-226.

[38] Olmeda P, Martin J, Garcia A, Villalta D, Warey A, Domenech V. A Combination of Swirl Ratio and Injection Strategy to Increase Engine Efficiency. SAE International Journal of Engines 10(3):2017, doi:10.4271/2017-01-0722.

[39] AVL manufacturer manual. Smoke value measurement with the filter-papermethod. Application notes. June 2005 AT1007E, Rev. 02. Web: https://www.avl.com/documents/10138/885893/Application+Notes.

[40] DRIVVEN Stand Alone Direct Injector Driver System User's Manual October 2010. Drivven, INC. 12001 Network Blvd, 110. San Antonio, Texas 78249. Web: www.drivven.com

[41] Payri F, Olmeda P, Martín J, García A. A complete OD thermodynamic predictive model for direct injection diesel engines. Applied Energy, Volume 88, Issue 12, December 2011, Pages 4632-4641.

[42] Payri F, Olmeda P, Martin J, Carreño R. A New Tool to Perform Global Energy Balances in DI Diesel Engines. SAE International Journal of Engines 7(1):2014, doi:10.4271/2014-01-0665.

[43] Splitter D, Hanson R, Kokjohn S, Wissink M, Reitz R. Injection Effects in Low Load RCCI Dual-Fuel Combustion. SAE Technical Paper 2011-24-0047, 2011, doi:10.4271/2011-24-0047.

[44] Wang Y, Yao M, Li T, Zhang W, Zheng Z. A parametric study for enabling reactivity controlled compression ignition (RCCl) operation in diesel engines at various engine loads. Applied Energy, Volume 175, August 2016, Pages 389-402.

[45] Benajes J, Pastor JV, García A, Monsalve-Serrano J. An experimental investigation on the Influence of piston bowl geometry on RCCI performance and emissions in a heavy-duty engine. Energy Conversion and Management, Volume 103, October 2015, Pages 1019-1030.

[46] Aceves S, Flowers D, Espinosa-Loza F, Martinez-Frias, Dec J, Sjöberg M, Dibble R, Hessel R. Spatial Analysis of Emissions Sources for $\mathrm{HCCl}$ Combustion at Low Loads Using a Multi-Zone Mode. SAE Technical Paper 2004-01-1910, 2004, doi:10.4271/2004-01-1910.

\section{Abbreviations}

ASTM: American Society for Testing and Materials

ATDC: After Top Dead Center

CAD: Crank Angle Degree 
CA50: Crank angle at 50\% mass fraction burned

CDC: Conventional Diesel Combustion

CO: Carbon Monoxide

CR: Compression Ratio

DI: Direct Injection

DPF: Diesel Particulate Filter

ECU: Electronic Control Unit

EGR: Exhaust Gas Recirculation

EVO: Exhaust Valve Open

FSN: Filter Smoke Number

HC: Hydro Carbons

$\mathrm{HCCl}$ : Homogeneous Charge Compression Ignition

IMEP: Indicated Mean Effective Pressure

IVC: Intake Valve Close

IVO: Intake Valve Open

LTC: Low Temperature Combustion

MCE: Multi Cylinder Engine

MPRR: Maximum Pressure Rise Rate

OEM: Original Equipment Manufacturer

ON: Octane Number

PFI: Port Fuel Injection

PPC: Partially Premixed Charge

PRR: Pressure Rise Rate

RCCl: Reactivity Controlled Compression Ignition

RoHR: Rate of Heat Release

SOC: Start of Combustion

SCE: Single Cylinder Engine

SCR: Selective Catalytic Reduction 